\title{
Replacing coal with wood: sustainable, eco-neutral, conservation harvest of natural tree-fall in old-growth forests
}

\section{An editorial essay}

\section{Leonard Ornstein}

Received: 17 May 2008 / Accepted: 28 April 2009 / Published online: 19 August 2009

(C) The Author(s) 2009. This article is published with open access at Springerlink.com

\section{Introduction}

The beginnings of the industrial revolution and global warming coincide with the replacement of wood by coal. Is it time to reverse this process, as a way of implementing "Biosphere carbon stock management" (Read 2008)?

The construction of new, coal-burning plants, utilizing carbon capture and sequestration (CCS), is now favored as a likely avenue to control global warming. However, modifying existing coal-burning plants, where the bulk of coal will continue to be burned for some time, is considered to be uneconomical (Gough and Shackley 2005). Modifications to allow the fueling of existing plants with cleanburning, renewable 'wood-chips' and charcoal, ${ }^{1}$ in place of coal, is a different proposition-technologically, economically (Bergman and Zerbe 2008; Marland and Schlamadinger 1997) and with respect to global warming. But it is not obvious where enough wood, that could be harvested sustainably, might be found to begin to replace coal.

Deforestation and degradative land abuse inject about 1.6 gigatonnes of carbon per year $(\mathrm{GtC} / \text { year })^{2}$ into the atmosphere as $\mathrm{CO}_{2}$, a greenhouse gas (GHG), (Alley et al. 2007). Halting deforestation is the principal forest-management tactic proposed to mitigate this contribution to global warming. The position of groups like the World

\footnotetext{
${ }^{1}$ Charcoal is an attractive storage alternative to wood. It is compact and burns very cleanly. Like all bio-char (Lehmann et al. 2006), it is uniquely resistant to degradation by organisms. The only threat, during storage in air, is its susceptibility to destruction by accidental fire.

${ }^{2} \mathrm{tC}=$ metric tonne carbon $=$ megagrams carbon $=10^{6}$ grams carbon; $\mathrm{GtC}=$ gigatonne carbon $=$ $10^{9} \mathrm{tC} ; \mathrm{ha}=10^{4} \mathrm{~m}^{2}$.
}

L. Ornstein $(\bowtie)$

Mount Sinai School of Medicine, NYC, 5 Biltom Road, White Plains, 10607, NY, USA

e-mail: lenornst@pipeline.com 
Wildlife Fund, Sierra Club, and the Rainforest Action Network is, 'Don't mess with the remaining old-growth forests!'

Below is an outline of a biologically-motivated conservation strategy for the management of such climax forests that might yield

a large, sustainable supply of wood,

further motivation for the cessation of deforestation and

up to as much as $4.6 \mathrm{GtC} /$ year in drawdown of $\mathrm{CO}_{2}$, with very minimal ecological impact:

\section{The core of the model}

Enormous numbers of trees fall 'naturally' each year in the world's remaining oldgrowth forests. In moist tropical forests, these decay, on average, within a few $(d)$ years, and release their minerals to the soil and their carbon to the atmosphere, as $\mathrm{CO}_{2}$. If most of these trunks were carefully harvested, shortly after they fell, they could be stored 'permanently' preventing decay and conversion to $\mathrm{CO}_{2}$; e.g., anoxic storage in sealed 'containers'; dry, under oxygen-free- $\mathrm{N}_{2}$ and/or $-\mathrm{CO}_{2}$, or wet, under oxygen-free, slightly acidic water. Anaerobic storage prevents the growth of fungi, which are the initiators of the attack on wood and bark. Such storage is much cheaper and safer than the proposed CCS storing of captured, pressurized $\mathrm{CO}_{2}$ at great depths underground or under the ocean.

Alternatively, they could be stored conventionally for use as a sustainable replacement for fossil fuel.

If stored but not burned, the harvest would contribute to a drawdown of atmospheric $\mathrm{CO}_{2}{ }^{3}$ starting at (harvest tC) $/ d /$ ha/year, and leveling off at the rate of (harvest $\mathrm{tC}$ )/ha/year, beyond the first $d$ years. Within a given area, net primary

\footnotetext{
${ }^{3}$ There is considerable confusion, at least among policy-makers and the general public, regarding under what conditions, and by what amounts, crops, forests and/or fuels derived from them, might or might not contribute to draw down in the amount of $\mathrm{CO}_{2}$ injected into the atmosphere. The following analysis may help to put things into perspective:

When land is cleared (cl) and a new crop is established, the carbon of the old-cover (grass, trees, etc.) is usually released, through decay or burning, as $\mathrm{CO}_{2}$, as a first (1), one-time-event, which we will designate as (cl1 tC/ha), where (cl1) stands for the amount of carbon released as $\mathrm{CO}_{2}$, after decay and/or burning, and ( $\mathrm{tC} / \mathrm{ha})$ stands for tonnes of carbon per hectare. In addition, there will be a second, (2), one-time release of $\mathrm{CO}_{2}(\mathbf{c l} 2 \mathrm{tC} / \mathrm{ha})$ from the energy expended to clear the land. The continuing original Net Primary Productivity (NPP) of the old (o) cover (NPPo tC/ha/yr) is also eliminated. It is replaced by a new (n) crop with a different average NPP (NPPn tC/ha/yr). If NPPn is less than NPPo, there will be a net, permanent increase in annual release of $\mathrm{CO}_{2}$ into the atmosphere, as is typical following deforestation. The maintenance (m) of the new crop (any cultivation, irrigation, fertilization, harvest, transportation, etc.) utilizes energy that contributes an additional ( $\mathbf{m ~ t C} / \mathrm{ha} / \mathrm{yr})$. The continuing impact/yr over a period of time, $\mathbf{d}$, following clearing $\left(\mathrm{CO}_{2}\right.$ footprint/yr) is something like [m tC/ha/yr $+(\mathbf{N P P o}-\mathbf{N P P n}) \mathrm{tC} / \mathrm{ha} / \mathrm{yr}+(\mathbf{c l 1}+\mathbf{c l 2}) / \mathbf{d} \mathrm{tC} / \mathrm{ha} / \mathrm{yr}]$.

When a natural perennial cover (prairie, savanna, forest, etc.) is itself harvested sustainably for fuel, the total will be about [m tC/ha/yr - (fraction of NPPo harvested) $t \mathrm{C} / \mathrm{ha} / \mathrm{yr}$ ] because the fraction harvested is regenerated by new growth.

When a previously barren area $(\mathbf{N P P o}=0, \mathbf{c l 1}=0, \mathbf{c l} \mathbf{2}=0)$ is afforested or put into sustainable agricultural production, the total $\mathrm{CO}_{2}$-footprint/yr will be about (m tC/ha/yr $-\mathbf{N P P n} \mathrm{tC} / \mathrm{ha} / \mathrm{yr}$ ), even if not harvested, because all net production is above the zero barren baseline. So long as $\mathbf{m}$ is small, this can provide a very substantial decrease in atmospheric $\mathrm{CO}_{2}$ (see Ornstein et al. 2009).
} 
productivity (NPP) is defined as the difference between the carbon sequestered through photosynthesis and the carbon released as $\mathrm{CO}_{2}$ due to respiration. Thus, when decay of the fallen trees is prevented, the harvest itself represents an increase in NPP.

On the other hand, if burned to replace fossil fuel, in existing ${ }^{4}$ plants, the just 'computed' drawdown of atmospheric $\mathrm{CO}_{2}$ would hardly be diminished, because the burning of equal masses of fossil-fuel-carbon or dry wood-carbon produce the same amounts of $\mathrm{CO}_{2}$ and very nearly the same amounts of energy (Bergman and Zerbe 2008). Therefore, burning, in lieu of coal or heavy fuel oil, and to a lesser extent natural gas and lighter burning oils, and long-term safe storage are 'substitutes' that 'equally' reduce the atmospheric load of $\mathrm{CO}_{2}$. Of course, storage costs are minimized if most of the harvest is consumed as fuel. Much 'storage function' is served-and saved-by leaving the fossil fuel in the ground.

In either case, removal of the wood also removes the mineral content of the harvested trunks from the local forest biome. Applying the 'wood-ash-equivalent' of each tree-trunk, representing approximately $1 \%$ of dry mass, to each harvest site would cancel that recycling deficit and should make the harvest 'indefinitely' sustainable. That ash-equivalent 'fertilizer' may come from previously burnt organic waste or wood or from mineral sources. Such harvest would then be 'eco-neutral' in its impact (see Section 5).

I call this a sustainable, eco-neutral, conservation harvest (SENCH). SENCH was accidentally 'discovered' during preliminary analysis of somewhat different strategies of how best to manage very large tree-harvests in a sustainable way. These harvests involve about $8.8 \times 10^{8}$ ha of proposed, irrigated tree-plantations on the Sahara and Australian Outback deserts (Ornstein et al. 2009). An eco-friendly, uneven-aged, harvest strategy, similar to that developed for northern hardwood old-growth forests (Keeton 2006), may be an attractive alternative approach with similar yields.

\section{How much carbon is involved?}

The areas of old-growth, broad-leaf, evergreen, rain forests of the Amazon and Equatorial Africa, harboring some of the ecologically richest biomes on Earth, coincidentally also total about $8.8 \times 10^{8}$ ha (Lewis 2006). The above ground biomass (AGB) of such forests averages about 200 to $350 \mathrm{t} /$ ha (Mahli et al. 2006) (equal to about 100 to $175 \mathrm{tC} / \mathrm{ha}$ ), of which about $2 / 3$ is in tree-trunks. Tree mortality rates in those forests run about $1.5 \%$ of biomass/year (Carey et al. 1994; Phillips and Gentry 1994). The harvest of fallen trunks could yield something like 1.0 to $1.75 \mathrm{tC} / \mathrm{ha} / \mathrm{year}$.

cl1, can be huge when forest is clear-cut, whereas cl2 usually is comparatively small. For crops like corn, $\mathbf{m}$ is often a substantial proportion of NPPn, but for new forests, it is usually a very small fraction.

${ }^{4}$ Fossil fuel contributes to its $\mathrm{CO}_{2}$-footprint/yr in proportion to its carbon mass, $\mathbf{p}$ tC/yr. Extracting and transporting it consumes a small additional mass, $\mathbf{q} \mathrm{tC} / \mathrm{yr}$, for most coal, gas and oil, but extraction constitutes a substantially larger fraction for tar-sands and very much larger fraction for oil-shale. Permanently replacing fossil fuel with bio-fuel often means that the new $\mathrm{CO}_{2}$-footprint/yr of an existing power plant depends mainly upon the magnitude of (NPPo $-\mathbf{N P P n}+\mathbf{m})$ compared to $(\mathbf{p}+\mathbf{q})$. When NPPn is smaller than $(\mathbf{N P P o}+\mathbf{m})$, the $\mathrm{CO}_{2}$-footprint/yr often will not be reduced when bio-fuel substitutes for fossil fuel. 
This is equal to a local increase of NPP of about 1 to $1.75 \mathrm{tC} / \mathrm{d} / \mathrm{ha} / \mathrm{year}$. A continuing total harvest, beyond $d$ years, just from these two geographic regions, would reduce released $\mathrm{CO}_{2}$ by about 0.88 to $1.54 \mathrm{GtC} /$ year-whether stored or burned in existing plants in place of fossil fuel.

Compared to the present increment of about $8.8 \mathrm{GtC} / y e a r$ injected into the atmosphere as $\mathrm{CO}_{2}$ from the combined world-wide burning of fossil fuels, deforestation and land abuse (Alley et al. 2007), the 0.88 to $1.54 \mathrm{GtC} /$ year is significant. This could begin to provide substantial mitigation of warming, especially if combined with an end to deforestation and with the application of other conservation practices such as the maximizing of industrial-, transportation- and home-energy-useefficiencies. Also, it might be amplified two or three times, as discussed below under Section 6.

\section{Economic and additional ecological costs and risks of SENCH}

Extraction of high-value wood is one of the motives that contributes to ongoing tropical deforestation. I have not assessed the amounts in those forests. But nonfuel uses for the most valuable wood among the fallen trees can reduce the net cost of SENCH. Counteracting this are increased costs of transportation of logs and the much smaller amount of 'ash', over global distances, rather than the transportation of coal, usually over shorter distances. These transportation differences will often contribute to the largest cost-disparity between wood and coal for countries-like the US - with ample domestic coal and far from the Amazon or Congo. The burning of fuel for any extra transportation of wood and ash will generate some additional $\mathrm{CO}_{2}$ that also will offset the net $\mathrm{CO}_{2}$-savings of 'renewable wood' by up to a few per cent. And the greater the care in removal of trees, the greater the economic cost, but the lower the ecological cost.

The following are some eco-friendly harvesting options:

Reduced impact logging (RIL) uses narrower logging-roads and narrow skid trails for removing trunks (Asner et al. 2004).

Skyline yarding, that might be employed for an advanced form of RIL, uses above-canopy, mobile towers and cables, requires fewer skid trails and permits more widely-spaced logging-roads. But it requires higher capital and operating costs and better-trained manpower.

The most ecologically benign approach, uses satellite location of new canopy gaps (Clark et al. 2003), and aerial transfer of logs to yards beside roads or rivers, using lighter-than-air ships (e.g., see Boeing SkyHook 2008) or helicopters. This permits removing the harvest by the use of only very widely-spaced logging-roads or, instead, rivers. Though it may be the most expensive strategy, it minimizes access for illicit harvesting or damage and may therefore significantly reduce policing costs.

A portion of the sum of RIL costs, policing costs, storage costs, transportation costs and 'chipping' and drying costs may need to be 'subsidized' with fossil-carbontaxes to make wood cost-competitive with fossil fuels-particularly with coal. These considerations also apply, although unequally, whether the harvest is 'permanently' stored, or used in place of fossil fuel. 


\section{Eco-neutrality?}

If an old-growth forest were truly at steady-state, by definition its yearly NPP would average zero. A fallen-trunk-only harvest strategy therefore would be expected to have a positive effect on NPP but a very minimal impact on biodiversity. Harvesting standing dead trees ("snags") should be intentionally avoided, because these survive decay a good deal longer than fallen trees. And snags are host to numerous unique and often rare species that should be conserved. On the other hand, in moist tropical forests the fallen trunks are rapidly degraded by the same organisms that degrade the branches, intentionally left behind as litter by SENCH. Therefore, only small shifts in the frequencies of the ubiquitous species that participate in these degradative processes should result as a consequence of SENCH.

In a truly steady-state forest, the ecological impact, if any, of such a harvest could be monitored in a straightforward manner. But all recent evidence (e.g., Zhao et al. 2007) indicates that most old-growth forests are, in fact, exhibiting substantial net growth for whatever reasons. The tropical rain forests have NPPs of 800 $1200 \mathrm{gC} / \mathrm{m}^{2} /$ year $\approx 10 \mathrm{tC} /$ ha/year (see Fig. 1 ). That means their ecologies are in flux. Therefore, biological impacts of a presumed eco-neutral harvest might be more difficult to measure.

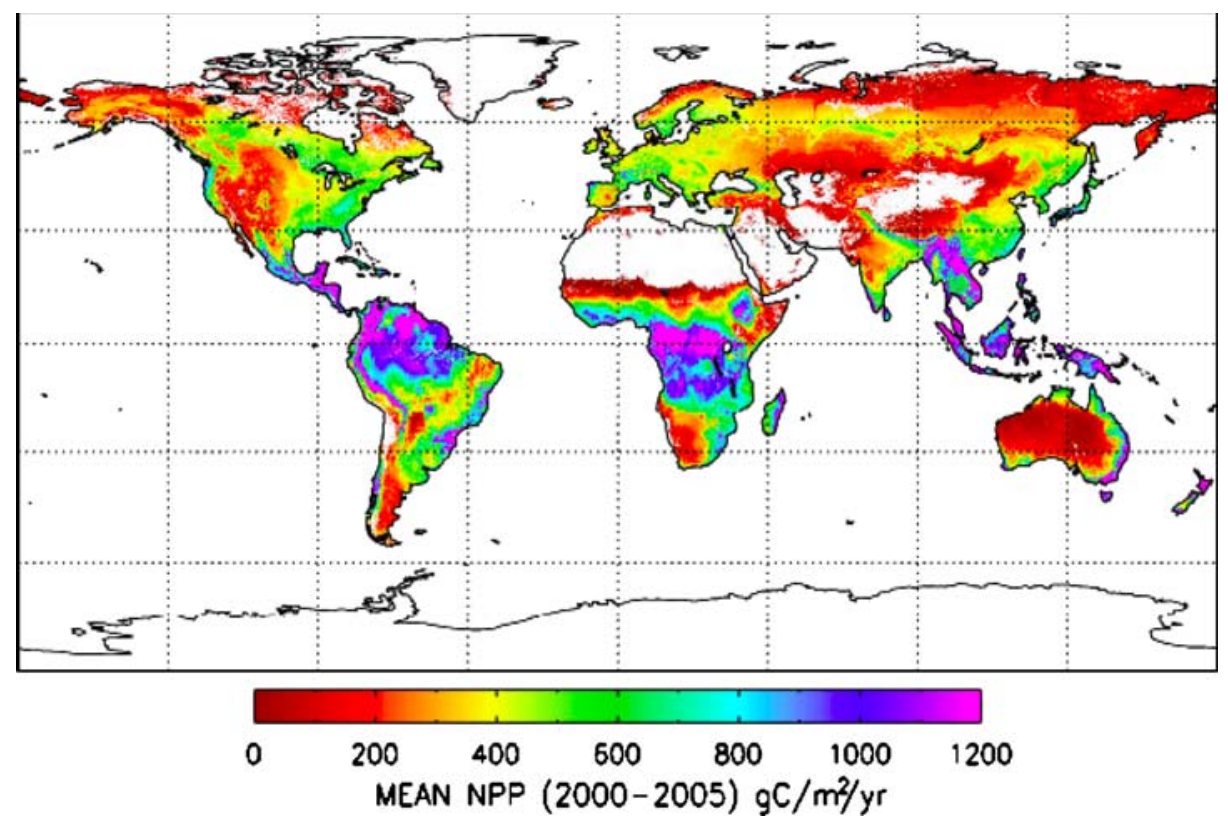

Fig. 1 From Zhao et al. (2007) 


\section{Further opportunities and risks to be explored}

Harvest only of fallen trees can be almost ecologically neutral and can drawdown atmospheric $\mathrm{CO}_{2}$ while providing a large, sustainable supply of wood to substitute for fossil fuels.

But even well-managed harvest of live trees in old-growth forests could be the beginning of deforestation with its well-known disadvantages; increasing atmospheric $\mathrm{CO}_{2}$ leading to global warming, the destruction of ecological networks and potential extinctions.

Is there any strategy for limited, near-eco-neutral harvest of live trees? Such harvest should at least not increase atmospheric $\mathrm{CO}_{2}$, but sustainably further increase the supply of wood to substitute for fossil fuel or, in the case of valuable timber species, perhaps substitute for logging operations elsewhere.

Suppose, along with the fallen trees, numbers of live trees were harvested, selected to both match the species and the size/age frequencies of fallen trees. Then the site-of-harvest would simultaneously be selected to widen those gaps in the canopy created by the recently fallen trees. This would increase illumination of the already exposed understory to further stimulate rapid re-growth. If the NPP of those stimulated and ash-fertilized understory trees quickly rises to at least equal that of the harvested live trees, drawdown of $\mathrm{CO}_{2}$ would not diminish and such increased harvest will be sustainable from year to year. Again, as with SENCH, it can be stored or used to replace coal, with about the same reduction in global warming. But the larger the harvest, the larger the ecological disturbance.

An incremental harvest of live trunks of about twice the mass of fallen trunks would leave a total mass of branches, as litter, that would be about equal to that of the total mass of the fallen trees in the untouched old-growth forest. This means the natural ecology of the above-ground detritus biome would be only marginally perturbed. However, the area of canopy gaps would increase to about three times that created by natural tree-fall. In the first year, the canopy biome would still be about $95 \%$ of the size of the original and barely perturbed. But the gap biome would be enlarged by $200 \%$.

Harvest of such magnitude may be sufficiently 'eco-neutral' to be encompassed under SENCH. Careful modeling (e.g., like in Marland and Schlamadinger 1997) might be used to establish some confidence in the magnitudes of projected yields and sustainabilities of various very-restricted dead-tree + live-tree SENCH scenarios. The fallen-tree-only SENCH strategy is likely to maintain the well-known skewed distribution of old-growth forests, with respect to species, age and biomass, where a few old and massive emergents represent a very large proportion of the biomass, and the average age and size are biased to high values. Over centuries or millennia, regularly harvesting even a few live trees would almost certainly lower those average values and modify the ecology, hopefully only slightly.

Such 'conservation' efforts unfortunately run the risk of failing catastrophically. If the market for wood is strong, some will be motivated to cheat and over-harvest. Effective enforcement, and perhaps costly policing, would be required to prevent such illegal 'poaching'. Failing enforcement, this could lead to the rapid destruction of remaining forests and to runaway global warming. However, satellite observation is cheap and it can detect features the size of forest clearings. Communication to enforcement agencies could be quick, and policing effective, if the political will is there. 
Of course, the planet is already running such risk without SENCH. Deforestation is a problem that is being faced quite widely (see the Forest Now Declaration 2007) under the rubric of REDD (Reduced Emissions from Deforestation and Degradation). However, I believe that political and economic mechanisms previously proposed in such contexts are not especially promising.

\section{Comparisons and politics}

Compared to the expensive replacement of most operating coal-fired power plants with CCS power plants and/or nuclear fission plants (two "Faustian Bargains" that risk uncertainties in the natural, long-term containment of 'dangerous wastes'; Spreng et al. 2007), the technology to implement SENCH already exists, is cheap and is direct-but it depends on effective policing. It could be exploited in forests much sooner than vast CCS replacement. Therefore, it could begin to reduce the rate of increase of atmospheric $\mathrm{CO}_{2}$ sooner. This is because the maximum rate of reduction of atmospheric $\mathrm{CO}_{2}$ follows the first 'harvest-rescue' by $d$ years, and is almost the same, whether the harvest is stored, while the politics of if and when to burn wood in place of coal is debated, or whether such policy is promptly instituted and the harvest is routinely used as fuel.

The politics of CCS and of old-growth-forest SENCH are quite different. Each presents its own set of difficulties. The risks, uncertainties and costs of the respective storage problems may create quite different levels of political resistance. And renewable resources, like forests, must be managed prudently and vigorously to remain sustainable, representing quite a different problem from managing power plants and burying pressurized $\mathrm{CO}_{2}$.

However, the SENCH strategy also could create significant employment and corporate opportunities in Amazonia and equatorial Africa, from:

logging and lumber production;

manufacture of charcoal, syngas, methyl alcohol and 'biodiesel', using anoxic pyrolysis;

safe storage of wood or charcoal;

manufacture of flexible fuel vehicles;

the export of these commodities;

'wood'-burning power plants;

forest management;

others.

These could provide competing economic incentives to replace those currently responsible for the world's largest deforestations in these same two regions; "killing two birds with one stone".

With appropriate taxes on fossil fuels, and with wood and/or charcoal substituting for coal, a substantial shrinkage of the world-wide coal industry would probably follow. Those taxes may also stimulate the more efficient production from wood, beyond classic anoxic pyrolysis, of 'new' renewable liquid and gaseous hydrocarbon fuels (e.g., Carlson et al. 2008; Ryan et al. 2008) and of feedstocks for organic syntheses. I believe such must ultimately serve as the main sustainable substitutes 
for the non-renewable GHG-generating supplies of fossil oil and natural gas that all agree are being depleted rapidly.

In summary, the SENCH strategy not only can lower atmospheric $\mathrm{CO}_{2}$, as does CCS, but simultaneously provides an alternative supply of renewable reduced carbon at low cost, probably with smaller risks, and at the same time, may further motivate forest conservation.

\section{Conclusions}

A SENCH strategy, combined with increasing energy-use efficiencies, might provide a breathing spell for the further development of other attractive 'solutions' to global warming; e.g., $\mathrm{CO}_{2}$-free sources of energy, such as cheaper 'solar' with cheap energystorage and/or, best of all, controlled fusion and a more rapid approach towards zero population growth.

$\mathrm{CO}_{2}$-free energy sources may fail to contribute quickly enough to allow all nations, and particularly China and India, to wean themselves from fossil fuels. Wide-spread use of CCS and expansion of the nuclear fission industry, both with risks and high costs, may then need to be instituted. (Note: CCS power plants fueled with SENCH wood almost double their effective carbon sequestration; they emit very little $\mathrm{CO}_{2}$, and through the increase in effective NPP of SENCH, can contribute twice the negative carbon footprint per watt of a standard CSS plant that replaces an existing coal burning plant; and half that, for a plant that adds to net power output.)

Alternatively, another SENCH-related solution that we have proposed, "Irrigated Afforestation of the Sahara and Australian Outback to End Global Warming" (Ornstein et al. 2009) could be initiated to renewably sequester about 8 additional $\mathrm{GtC} / \mathrm{yr}$. We had suggested CCS or nuclear-fission to power the sea-water desalination plants and pumps needed to supply fresh irrigation water to the 'desert forests'. To avoid the associated Faustian Bargain (Spreng et al. 2007) and to reduce capital costs, such coal-fueled, power plants might instead be fueled with SENCH wood, without CCS or with CCS, to further lever the effectiveness of the overall system in removing carbon from the atmosphere.

However, if SENCH wood is to replace coal, effective policing and taxing of high$\mathrm{CO}_{2}$-footprint biofuels and excessive harvest and use of other wood, both tropical and non-tropical, that is neither eco-neutral nor forest-preserving, may become very difficult (see Wise et al. 2009).

Open Access This article is distributed under the terms of the Creative Commons Attribution Noncommercial License which permits any noncommercial use, distribution, and reproduction in any medium, provided the original author(s) and source are credited.

\section{References}

Alley R et al (2007) IPCC summary for policy makers. (IPCC Secretariat, Geneva Switzerland). http://www.ipcc.ch/pdf/assessmentreport/ar4/syr/ar4_syr_spm.pdf

Asner GP, Keller M, Silvas JNM (2004) Spatial and temporal dynamics of forest temporal gaps following selective logging in the eastern Amazon. Glob Chang Biol 10:765-783 
Bergman R, Zerbe J (2008) Primer on wood biomass energy. Forest Products Laboratory, Forestry Service, USDA, pp 1-10. http://www.fpl.fs.fed.us/tmu/resources/documents/ primer_on_wood_biomass_for_energy.pdf

Boeing SkyHook (2008) http://boeingmedia.com/imageDetail.cfm $?$ id $=15279 \& \mathrm{clr}=$ release

Carey E, Brown S, Gillespie AJR, Lugo AE (1994) Tree mortality in mature lowland tropical moist and tropical lower montane forests of Venezuela. Biotropica 26:255-265

Carlson TR, Vispute TP, Huber GW (2008) Green gasoline by catalytic fast pyrolysis of solid biomass derived compounds. ChemSusChem 1. doi:10.1002/cssc.200800018

Clark DB, Castro CS, Alvarado LDA, Read JM (2003) Quantifying mortality of tropical rain forest trees using high-spatial-resolution satellite data. Ecol Lett 7:52-59

Forest Now (2007) Forest Now Declaration. http://www.forestsnow.org/

Gough C, Shackley S (2005) An integrated assessment of carbon dioxide capture and storage in the UK. Technical report 47, Tyndall Project T2/21, October. http://tyndall.ac.uk/ research/theme2/final_reports/t2_21.pdf

Keeton WS (2006) Managing for late-successional/old-growth characteristics in northern hardwoodconifer forests. For Ecol Manag 235:129-142

Lehmann J, Gaunt J, Rondon M (2006) Bio-char sequestration in terrestrial ecosystems-a review. Mitig Adapt Strategies Glob Chang 11:403-427

Lewis SL (2006) Tropical forests and the changing earth system. Phil Trans R Soc B 361:195-210

Mahli Y et al (2006) The regional variation of aboveground live biomass in old-growth Amazonian forests. Glob Chang Biol 12:1107-1138

Marland G, Schlamadinger (1997) Forests for carbon sequestration or fossil fuel substitution? A sensitivity analysis. Biomass Bioenergy 13:389-397

Ornstein L, Aleinov I, Rind D (2009) Irrigated afforestation of the Sahara and Australian outback to end global warming. Clim Change. doi:10.1007/s10584-009-9626-y

Phillips OL, Gentry AH (1994) Increasing turnover rates through time in tropical forests. Science 263:954-958

Read P (2008) Biosphere carbon stock management: addressing the threat of abrupt climate change in the next few decades: an editorial essay. Clim Change 87:305-320

Ryan MW, Liu ZY, Peter M, Dumesic JA (2008) Liquid alkanes with targeted molecular weights from biomass-derived carbohydrates. ChemSusChem 1. doi:10.1002/cssc.200800001

Spreng D, Marland G, Weinberg AM (2007) $\mathrm{CO}_{2}$ capture and storage: another Faustian Bargain? Energy Policy 35:850-854

Wise M, Calvin K, Thomson A, Clarke L, Bond-Lamberty B, Sands R, Smith SJ, Janetos A, Edmonds $\mathrm{J}$ (2009) Implications of limiting $\mathrm{CO}_{2}$ concentrations for land use and energy. Science 324:11831186

Zhao M, Nemani R, Running S (2007) MODIS GPP/NPP Project (MOD17). http://secure.ntsg. umt.edu/projects/index.php/ID/ca2901a0/fuseaction/projects.detail.htm 